University of South Florida

DIGITAL COMMONS

Digital Commons @ University of

@ UNIVERSITY OF SOUTH FLORIDA

South Florida

QMaSC: A Handbook for Directors of

Quantitative and Mathematics Support Centers

USF Libraries

$1-1-2016$

\title{
28. Case Study: Quantitative and Symbolic Reasoning Center at Hamilton College
}

Mary B. O'Neill

Hamilton College

Follow this and additional works at: https://digitalcommons.usf.edu/qmasc_handbook

\section{Recommended Citation}

Mary B. O'Neill (2016), "Case Study: Quantitative and Symbolic Reasoning Center at Hamilton College", http://dx.doi.org/10.5038/9780977674435.ch28 in G. Coulombe, M. O'Neill, M. Schuckers (Eds.) A Handbook for Directors of Quantitative and Mathematical Support Centers, Neck Quill Press, http://scholarcommons.usf.edu/qmasc_handbook.

This Case Studies is brought to you for free and open access by the USF Libraries at Digital Commons @ University of South Florida. It has been accepted for inclusion in QMaSC: A Handbook for Directors of Quantitative and Mathematics Support Centers by an authorized administrator of Digital Commons @ University of South Florida. For more information, please contact digitalcommons@usf.edu. 


\title{
Case Study: Quantitative and Symbolic Reasoning Center at Hamilton College
}

\author{
(C) Mary B. O’Neill, \\ Hamilton College
}

प्र

\section{Introduction}

Hamilton College is a small, highly selective four-year liberal arts college, located in central New York. The college offers students an open curriculum, with no distribution requirements. There are, however, four graduation requirements: 1) complete a major, 2) pass three writing-intensive courses, 3) fulfill the Qualitative and Symbolic Reasoning (QSR) Requirement (one course), and 4) pass the physical education requirement. The college serves approximately 1800 undergraduate students from all over the country, but primarily the Northeast. According to information from the Office of Admission, students come from 46 states and 40 countries; more than one-quarter of the student body consists of diverse students from the U.S. or are international students. The most popular majors are economics, mathematics, government, biology, psychology, history, English/creative writing, and world politics. Hamilton College has a strong reputation of supporting excellent writing, quantitative literacy, and communications skills. Tutoring, collaborative learning, and academic support are looked on favorably and are encouraged as an integral part of student success. Other programs that offer academic support are the Nesbitt-Johnston Writing Center, the Oral Communication Center, Language Center, HEOP (Higher Education Opportunity Program), and ESOL (English for Speakers of Other Languages).

Suggested Citation: Mary B. O'Neill (2016), "Case Study: Quantitative and Symbolic Reasoning Center at Hamilton College", http://dx.doi.org/10.5038/9780977674435.ch28 in G. Coulombe, M. O'Neill, M. Schuckers (Eds.) A Handbook for Directors of Quantitative and Mathematical Support Centers, Neck Quill Press, http:// scholarcommons.usf.edu/qmasc_handbook.

This material is based upon work supported, in part, by the National Science Foundation under Grant DUE1255945. Any opinions, findings, and conclusions or recommendations expressed in this material are those of the author(s) and do not necessarily reflect the views of the National Science Foundation 
In the late 1970's, Hamilton received an IBM grant to, "investigate possible deficiencies in quantitative skills and to make recommendations, if appropriate, on how the college might remedy any such deficiencies." In 1984 The Quantitative Literacy Committee designed a written examination to be given to all incoming first-year students to test quantitative skills necessary to make informed judgments about problems that have an essential numerical content, skills that should be part of the "intellectual equipment of any educated citizen." This exam was intended as an advising tool. The department of mathematics also gave a placement exam to students who wished to take calculus, directing them to the appropriate calculus course. Ironically, students would often pass the calculus exam, but not the QSkills Exam.

Following its investigation and development of the quantitative skills exam, the committee recommended that the college establish a Quantitative Skills Tutorial Center. Students scoring below a certain cut-off would be advised to pursue studies, including tutoring at the center, to improve their quantitative skills. Student tutors were majors in biology, chemistry, economics, mathematics, and psychology. All tutors had a firm mathematical background.

From 1990 to 1993, the center was located in a classroom building separated from the Department of Mathematics. Because of classroom needs, it was moved to the building that housed the Department of Mathematics. This closeness to the math department helped, as students came in readily from the math classes held on the same floor. The name of the center was changed to the Quantitative Literacy Center (QLit. Center), and tutoring took place after 2:00 pm, when classes were no longer held in the space. An adjacent storage closet was set up as an office for the director. It was generally agreed that the location of the QLit. Center and of the office was a good one, as it was in the middle of the campus, and in a building that saw much student traffic; however, the facilities left much to be desired, most notably the size of the center and the director's office.

In 1995 the faculty voted to make quantitative literacy a requirement. To fulfill this requirement, by the end of their second year, students could either 1) pass the QSkills Exam (taking the exam is required of all students), 2) take a "Q" course, or 3) take a non-credit tutorial facilitated through the QLit. Center. Students who missed the exam and students who matriculated in the second semester were given the option of going to the center to take the exam individually. This was a time-consuming task for the director of the center. Students who did not pass the exam were not given the option of a retake.

The QLit. Requirement was replaced in 2009 when the faculty passed a new Quantitative and Symbolic Reasoning (QSR) Requirement. The guidelines for students in the class of 2014 and later state:

Hamilton expects that every student will demonstrate facility in quantitative and symbolic reasoning by completing one or more courses in at least one of the following three categories:

1. Statistical Analysis. The use of statistical analysis to describe data and to make inferences. 
2. Mathematical Representation. The use of mathematical models such as those based on graphs, equations and geometric objects to represent patterns, relationships and forms.

3. Logic and Symbolic Reasoning. The use of formal logic or symbolic reasoning such as in the following examples: the proper construction of a computer program or a formal proof; the analysis of language in linguistics; or the study of music theory.

This requirement should be fulfilled by the end of the second year at Hamilton College. https: //my.hamilton.edu/catalogue/academic-regulations\#StandardsforQuantitativeWork

In 2011, the center's name was changed to the Quantitative and Symbolic Reasoning Center (QSR Center) to reflect its support for the new QSR Requirement.

The current QSR Center is located in the Christian A. Johnson building, which also houses the Department of Mathematics, Study Abroad Offices, the Digital Humanities Center, and classrooms and offices for the departments of mathematics and languages. Information about the mission and role of the QSR Center can be found at https://my.hamilton.edu/qsr.

\section{Organization and Services}

Services provided by the QSR Center:

- Support for the QSR Requirement

- Drop-in and group peer tutoring in quantitative courses

- Space for study groups

- Self-paced modules for skills review

- Computer lab and printer

- Library of quantitative resources

- Topical quantitative workshops and review for post-graduate exams

- Help beyond professors' office hours

The QSR Center supports the QSR Requirement and the faculty by offering drop-in peer tutoring in introductory level courses containing a math/quantitative/symbolic component. Students are encouraged to form study groups and to meet in the center at a regular time when there is a tutor in their subject available. The center offers review sessions for various topics throughout the semester. Materials are available for review and for "how to study" in the various disciplines.

In addition to the original disciplines of chemistry, economics, mathematics, and psychology, help with biology, physics, philosophy (symbolic logic), and departments' stats courses have been added. When a tutor is qualified, other QSR courses are supported, such as Elements of Music. 
Statistics regarding QSR Center usage are calculated using student sign-in data. A student could be in for a short period of time or may stay for hours. During 2012-13, the courses served included Calculus (70\%), Chemistry (11\%), Economics (10\%), Physics (4\%), Philosophy (symbolic logic) (2\%), Psychology/Music (1\%). Biology and Computer Science take up the remainder. Total visits were 737 in the fall, and 446 in the spring, for a total of 1,183.

Students who need to go beyond the help at the center, or who need tutoring in subjects that are not offered at the center, may meet with the QSR Center director to request a one-on-one tutor through the Peer Tutoring Program. Information about that program is on the website https://my.hamilton.edu/peertutoring.

Center tutoring times have also changed since the beginning, from being open four hours a day Monday through Thursday, to almost 50 hours a week, closing on Saturday. Beyond the tutoring available, students have the opportunity to work on their own, work on the computers, use the printer, avail themselves of the library and resource materials, play out ideas and problems on the many white boards, sit in the lounge chairs and read, or to discuss their needs with the director.

The center is also a resource for departments and for faculty. Faculty may request that a special topic be covered; or request that a tutor meet with a class for a review session. The director may consult with faculty about the content of QSR courses that they teach or may meet with faculty to develop QSR aspects of their courses, whether they count towards the requirement or not. The center director, along with the QSR Committee, sponsors topical workshops, and brings in speakers on various QSR topics.

Periodic topical sessions are offered through the center, facilitated by the center tutors. During the 2012-2013 academic year, tutors planned and presented the "Math Commons." Students were invited to sit in on sessions covering the following topics: Personal Health and Fitness, Graphs and Charts, Personal Finance, and Algebra Review.

On a White Board, tutors can record "Top Topics" that have been covered during the day. Tutors and students can look at the board when they come in and see what is being worked on. A summary of top topics can be compiled and e-mailed to the appropriate faculty.

\section{Staffing, Hiring, and Training}

The staff of the QSR Center consists of a Director and peer tutors. Each year the director selects two or three upper-class experienced tutors as Senior Tutors, who help with tutor training, special planning, and data collecting.

Peer tutors are majors who have been recommended by the departments the center supports. Sometimes a student who is not a major, but who has done well in a particular course, is recommended. Tutors should have excellent academic and personal qualifications. All tutors must have taken calculus. Following a meeting and interview in the spring, the director examines the 
applicants' transcripts and references. The tutors are among the top students in the college who have a desire to work with their fellow students and to practice the academic and personal skills necessary to be good tutors and communicators. Approximately 24 tutors are hired for a year, but only about 18 or 19 of these tutors are active at any given time because many Hamilton students study abroad.

Tutors are trained in the early fall in the administrative and personal aspects of tutoring. The tutor guidebook details responsibilities and issues that may come up during a tutoring session. Topics include confidentiality, dealing with personal issues, using interpersonal skills to put students at ease, tutoring in a multi-cultural setting, dealing with students who "just want the answer," and what to do when you can't help a student. Tutors discuss what makes a good learner - they talk about the learning process and about the importance of study skills. There are periodic meetings with representatives from the departments that the center supports, as well as meetings in small groups to go over problems and to work on the challenges of tutoring several disciplines during a short period of time. Tutors also learn how to fill out report forms and time sheets properly. At end of each shift, the tutor fills out a form telling the date, time worked, topics covered, and number of students the tutor worked with. The tutors are asked to elaborate about what worked and what didn't, and how they chose to solve the problems. A group like this, working together for many hours and weeks, becomes like a family, and the atmosphere is not just serious and hard work - it is good for students to be part of this, too.

Much is said about the benefits of tutoring for tutees, but tutors gain much from the experience besides earning the top hourly wage on campus. Tutors get to review material, they develop administrative experience, they develop their interpersonal skills, build up their resumes, expand professional relationships with professors, develop new friendships, and help the college. QSR Center tutors are often valedictorians and salutatorians, and are selected for department honors honor societies. The director is often called upon for references for graduate school, medical school, fellowships, and more.

Prior to the 2013-2014 academic year, the position of director was a $\frac{3}{4}$-time, ten-month appointment. Now the center director holds a full-time ten-month, administrative position. The director reports to the Associate Dean of the Faculty and is an ex officio member of the QSR Committee. The director's responsibilities involve all aspects of running the center, soliciting and training of tutors, monitoring the tutorials, consulting with faculty, maintaining the center web site, and coordinating the one-on-one Peer Tutoring Program. The director will teach a "Q" course each year. The increase in responsibility is an indication of the commitment of the college to this academic requirement and support. 


\section{Community Interactions}

The Director of the QSR Center, along with other directors of Academic Support Centers at Hamilton who report to the Academic Dean, meet monthly to discuss issues that pertain to running academic support programs, such as budgets, reports, web site information, and other topics as they come up.

The director also works closely with departments that the center supports. Information about other departments' review sessions and support is kept up-to-date by the director; this information is posted on the center bulletin board. Course instructors are asked to put information about the QSR Center on their syllabi. The director meets with new faculty during New Faculty Orientation. The center also disseminates information to matriculating students during New Student Orientation in the fall and at the beginning of the spring semester for January admits and transfer students. The center is represented at Family Weekend, Fallcoming, Commencement, and at campus service days.

Center services are communicated to the college community via the web site, e-mail, fliers, class visits by center tutors, articles in the campus newspaper, Hamilton College web news, an annual open house, the Peer Tutoring Newsletter, and on Facebook.

The center director is an ex officio member of the QSR Advisory Committee, composed of faculty who teach QSR courses. This committee reports to the Dean of Faculty. Changes in the QSR Requirement and the QSR Program are made by the QSR Advisory Committee and are presented to the faculty via the Committee on Academic Policy.

The director attends meetings and conferences regarding quantitative support, such as NECQL (Northeast Consortium for Quantitative Literacy), JMM (Joint Math Meetings), and others.

\section{Assessment}

Student data is tracked by a sign-in program on a center computer located near the entrance. Students enter their names, class year, the date, course number, professor, and purpose of the visit. The list generated from this program is used to send out a questionnaire near the end of each semester.

Several years ago the Quantitative Literacy Program was part of an external assessment of the Department of Mathematics. Most of the comments and recommendations pertained to the Quantitative Literacy Requirement and the exam, both of which were perceived as weak and have since been strengthened. An external assessment specific to the QSR Center has not been done. 


\section{Additional Topics: A New Space}

In the spring of 2011 it was decided that the building housing the QSR Center would undergo major changes. The math department would move to the first floor to gain visibility and to have more study and work space for students. Three programs would take over the space on the first floor vacated by the museum of art. A space on the third floor that had been the Media Library was designated for the QSR Center.

The QSR Center director met with the associate dean, the head of physical plant, and the QSR committee, to discuss center needs. Most important was a larger space, more tables, and more computers, along with an area with a conference table for group work and presentations. The center needed a larger office for the director, including more room to move around in, to meet with students, and with adequate work surfaces. The challenge was to turn a windowless space into one where students could work comfortably. Outside walls on the third floor are three feet thick, so it would be impossible to break through to put in windows. However, architects' plans included breaking through inside walls to the hall in order to bring in light from the building's existing skylight and to create a spacious feeling to the center.

At a final tutor meeting at the end of the spring 2011 term, tutors were asked to envision their "ideal center," and to draw plans on large sheets of paper. They came up with some very practical ideas: more tables, a conference table, more computers, and white boards. They had fun adding extras, like a beanbag pit and a coffee shop. Below is a copy of one of the plans:

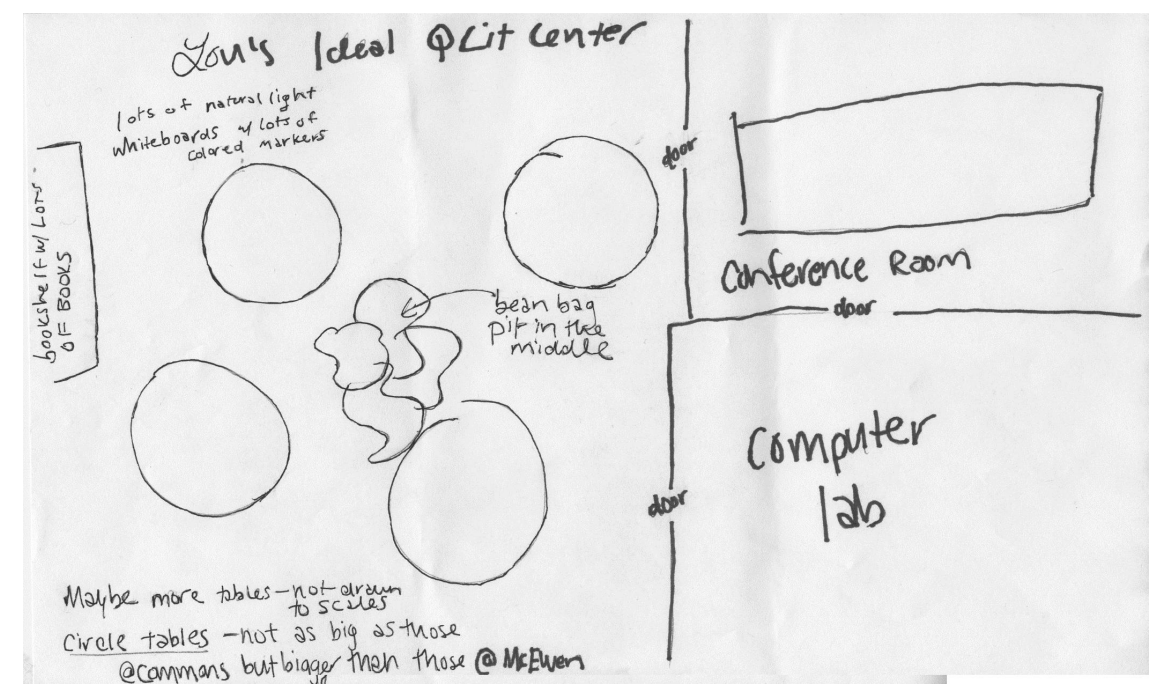

Figure 1: A student's ideal plan for the new center

Tutors especially liked the idea of many tables where they could quickly move from one student or group, to another. They also favored white boards over chalkboards. 
Below is a copy of one of the architect's renderings, with windows looking out to the hall.

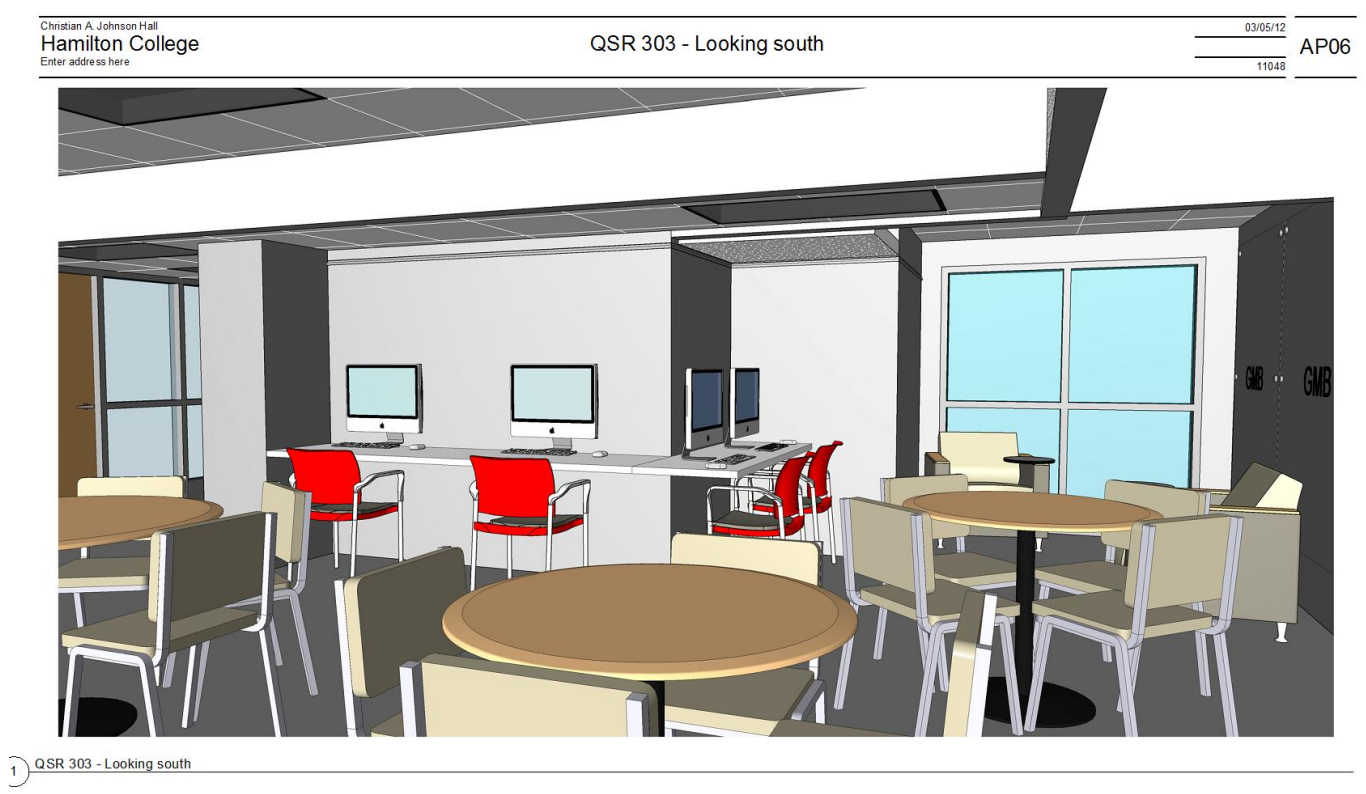

HOLTARCHIRECrS P.C.

Figure 2: Rendering by Chiang/O'Brien Architects

Since the new center was completed, students have exclaimed that the space is so bright, open, and inviting that they don't even notice the lack of windows to the outside. At the end of our first year of operation in the new space, tutors named things that surprised them about the center.

Surprises in the New Center:

- The whiteboards, round tables, rolling chairs

- The added exercise climbing up the two flights of stairs

- The brightness

- The large conference table is a great study space, where students can spread out their material

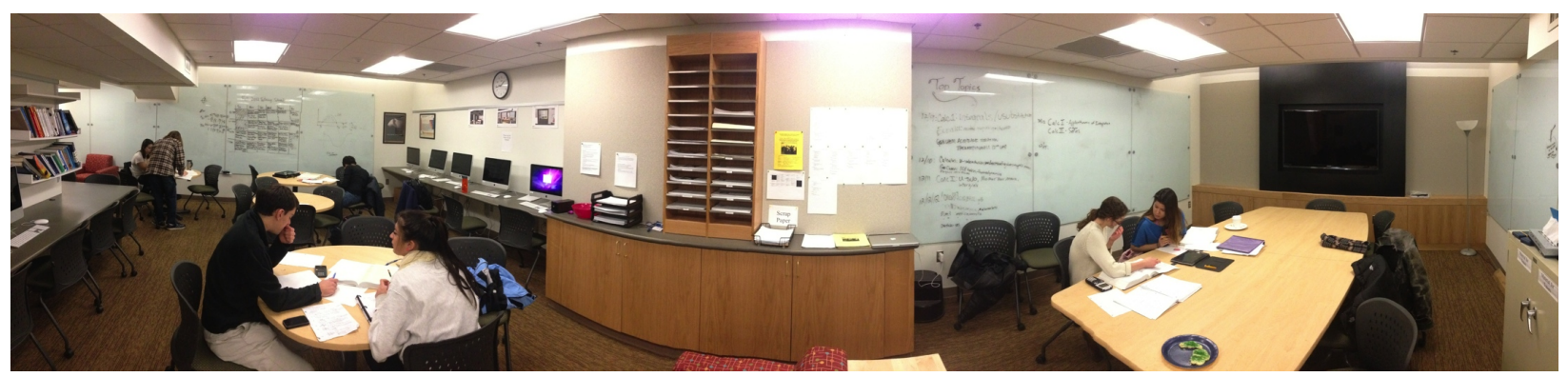

Figure 3: Photo by Max Schnidman, Hamilton '14, September 2013

Contrary to the fear that the climb to the third floor would keep students away, we served a 
steady stream of students throughout the 2012-2013 academic year. The new QSR Center is a valuable asset to the QSR Program and to Hamilton College's academic community.

\section{Acknowledgements}

I would like to thank the National Science Foundation for its generous support of the QMaSC Workshop through NSF grant number 1255945. Any opinions, findings, and conclusions or recommendations expressed in this material are those of the author and do not necessarily reflect the views of the National Science Foundation. I would like to thank my co-PI's Grace Coulombe and Michael Schuckers, whose humor and intelligence make it a pleasure to work on this project. I thank McKayla Nuffer, Assistant Director of the Peterson Quantitative Resource Center at St. Lawrence University, whose attention to detail and whose technical skills have provided significant support for this project. Thanks to Hamilton College and the Dean of the Faculty for their generous support and to the QSR Advisory Committee, especially Professor Tim Kelly. Finally, I would like to thank my husband, Professor John H. O'Neill, who was a member of the original Quantitative Literacy Committee, and whose support and encouragement have been overwhelming, not to mention his proof-reading abilities (yes, he is an English Professor!). 